\title{
Interdisciplinary teaching practices: Reflections from a teaching triangle
}

\author{
Melba Sheila D'Souza*1, Bala Raju Nikku², Cael Field ${ }^{3}$ \\ ${ }^{1}$ School of Nursing, Thompson Rivers University, British Columbia, Canada \\ ${ }^{2}$ Faculty of Education and Social Work, Thompson Rivers University, British Columbia, Canada \\ ${ }^{3}$ Faculty of Science, Thompson Rivers University, British Columbia, Canada
}

Received: October 14, 2020

DOI: $10.5430 /$ jnep.v11n5p10
Accepted: December 21, 2020 Online Published: January 10, 2021

URL: https://doi.org/10.5430/jnep.v11n5p10

\begin{abstract}
Background and aim: There is an increased understanding of and appreciation for teachers' work from other disciplines, primarily for formulating individual plans and enhancing one's teaching based on observations and shared reflections. This article reviews how reflective practice, which is self-initiated and focused, informs the understanding and improvement of teaching practices, demonstrates interaction with students, and guides teaching experiences. This article aims to explore reflective practices that were meaningful for engaging in in-class instructional teaching practices.

Methods: A self-study methodology was used to examine the complicated relationship between teaching and learning and knowledge in action of teacher education pedagogy.

Results and discussion: As teacher, we understand the importance of problem-solving, establishing connections between relationships, and motivating students to think about missing connections or reconsidering them. Implications: The benefit of the Teaching Triangle was enhancing interdisciplinary relationships, understanding professional teaching relationships, and learning from each other without boundaries.

Conclusions: Three aspects of the interdisciplinary reflective practice that emerged were adopting philosophy and purpose-driven goals; facilitating teaching pedagogy and technology; and creating culturally safe and effective student learning environments.
\end{abstract}

Key Words: Higher education, Instructional practices, Interdisciplinary, Peer review, Reflection, Reflective practices, Student engagement, Teachers, Teaching-learning, Teaching practices

\section{INTRODUCTION}

“A practitioner's reflection can serve as a corrective to over-learning. Through reflection, (s)he can surface and criticize the tacit understandings that have grown up around the repetitive experiences of specialized practice and can make new sense of the situations of uncertainty or uniqueness which (s)he may allow (her)himself to experience.,"[1]
Shulman ${ }^{[2]}$ argues that teaching needs to be treated and valued at similar levels as research - as public, community property - to be recognized as a credible scholarly activity. The purpose of reflection is for teachers to reflect on what they believe the best practice for teaching and learning in their classrooms. ${ }^{[3]}$ Reflective practice refers to the responsibility for contemplating teachers' practice, what they do, why they do it, and how they do it, inside or outside the

*Correspondence: Melba Sheila D’Souza; Email: mdsouza@tru.ca; Address: School of Nursing, Thompson Rivers University, British Columbia, Canada. 
classroom, in order to make the practice significant. ${ }^{[4]}$ As postsecondary teachers, we typically experience teaching as something that takes place exclusively behind closed doors and in front of our students.

This article reveals insights and reflections from a Teaching Triangle initiated for the first time in the fall semester of 2019 at Thompson Rivers University. This Teaching Triangle involved three interdisciplinary teachers, including the author, with each teacher visiting and observing each other's classes. The interdisciplinary teachers had integrated a community of inquiry model consisting of social, cognitive, and teaching presence focused on the student, teacher, and course outcomes in our teaching practice. Social presence is the student's ability to identify with the community such as a course of study, communicate purposefully in a trusting environment, and develop interpersonal relationships by way of protecting their personalities. ${ }^{[5]}$ Teaching presence is the design, facilitation, and direction of cognitive and social processes to realize personally meaningful and educationally worthwhile learning outcomes. ${ }^{[6]}$ Cognitive presence is the extent to which learners can construct and confirm meaning through sustained reflection and discourse. ${ }^{[6]}$ The process of community inquiry can facilitate an understanding of the complexities of building student relationships.

The process of reflection allows teachers to better understand and reshape what they teach. Peer observation of teaching through the Teaching Triangle prevents individual isolation of teachers as they overcome challenges, open their doors to colleagues, and allow for critical observations within their classrooms, thus generating critical discussions about teaching and learning, peer suggestions, and critical feedback. As interdisciplinary teachers, coming together to watch, analyze, critically discuss, review, and reflect on teaching also makes the complex and rigorous work of teaching and learning visible and communally relevant. Though time is a constraint for reflection, reflective practice is vital for developing professional practice. Engaging in evidence-based teaching practice enables teachers to reflect on themselves and others, what they do, how they do it, why context informed practice the impact of one's teaching on student learning.

The Teaching Triangle aimed to provide teachers with an opportunity to gain insight into self-teaching and actionoriented learning through a non-evaluative process of classroom visits and reflections. Classrooms can be sites for rewarding and meaningful interactions and learning and so a closed-door scenario is undesirable ${ }^{[7]}$ which creates an environment of isolation for teachers. This environment inhibits the rich dialogue and learning potential that can arise in conversations about teaching and learning with colleagues. ${ }^{[8]}$

Published by Sciedu Press
When teachers use reflective practice through their learning accounts, they become critical teachers. ${ }^{[9]}$

Teaching behaviors like being professionally competent in theoretical knowledge and clinical skills, developing interpersonal skills such as being genuine, caring, empathetic, respectful, and approachable, having teaching abilities, being accessible, answering queries, and helping to think critically - are essential for growth and development. ${ }^{[10]}$ A reflective practice model includes an examination of the technical aspects (one's practice), the internal aspects (philosophy, principles, and theory), the external aspects (social, cultural, and political settings in which they teach) and aspects beyond practice. ${ }^{[3]}$ The ability to engage in reflective activity is acknowledged as a feature of professional competence in incorporating reflection and reflective practice into their professional development. ${ }^{[11]}$

The Teaching Triangle is a reflective dialogue that is different from peer review in teaching. This article reviews our self-reflective practice, which is self-initiated and focused, as it informs our efforts to understand and improve our teaching practices and showcases our interaction with students and our own teaching experiences. The reflective practice's main goal is to enrich an informal process of peer learning and peer observation and personal experience from another teacher's classroom delivery of content.

\section{Methods}

This article aims to explore reflective practices that were meaningful for engaging in in-class instructional teaching practices. The main questions were: What have we learned about our teaching philosophy from each other's classroom visits? How has the experience of being in the "learner" role impacted our teaching practice? What was the one thing I have learned from the Teaching Triangle that would make my teaching more effective?

A self-study methodology was used to examine the complicated relationship between teaching and learning and moving beyond stories to develop knowledge of teacher education pedagogy. ${ }^{[12]}$ The self-study characteristics used were selfinitiation and self-focused, improvement-oriented, and interactive process, qualitative method, and trustworthiness. ${ }^{[13]}$ This self-study method included three interdisciplinary teachers in nursing practice, social work, and respiratory therapy who met with the common goal of reflecting on their observations and each other's teaching practices. The method involves narrative synthesis, validation, and triangulation with interdisciplinary teachers seeking to connect with analysis of and conclusions about teaching practices. This teaching approach of interdisciplinary collaborative practice is called 
the Teaching Triangle.

The opportunity provided by the Teaching Triangle to visit teachers' classrooms arose from September to December of fall 2019. Talking with the teachers before the class visits (pre-class) and reflecting with them to understand how they engaged through the case studies (during class) took place. The post-class reflections involved talking about practices and ways to motivate and engage students, using creativity and instilled critical thinking. Each of the teachers represented unique teaching practices drawn from different disciplines: nursing practice, social work, and respiratory therapy. Each teacher had their own identities, philosophies, principles, theories, experiences, and reflections. Their reflections were guided by the teachers' professional teaching, approachability, accessibility, and appropriateness in their particular contexts. The interdisciplinary Teaching Triangle focused on five components: reciprocity, shared responsibility, appreciation, self-referential reflection, and mutual respect. This refers to reflecting on what the participating teachers can learn from each other's teaching styles and, teachers with a passion for teaching and learning. At the end of the semester, the teachers reflected and shared their observations in an environment that was supportive for professional growth. The teachers continued to reflect on the application of experiential learning theory in their peer learning observation, classroom visitation, and reflection action plan.

The teachers' visited each other's classes, observed the teaching styles, classroom management, and teaching dynamics through a safe, respectful, and supportive lens. Each classroom visit involved the taking of field notes of teachers' and students' observations in the classroom for two hours, gathering teaching materials, and participating in the learning activities. The purpose of these classroom observations in the Teaching Triangle was explained to students for their consensus. Each teacher independently took observation field notes about the other participants' teaching activities. These observations allowed us to review and analyze classroom activities individually and then together as a group. Teachers facilitated conversation within the student peer groups by stimulating critical thinking, directing relevant research for knowledge, exploring ideas, and providing feedback. At the end of the case study, peer groups discussed the solutions to the case study through exchanging dialogue, eliciting feedback, and contributing to critical discourse. Reading and analyzing case studies, reinforcing knowledge, and generating ideas were essential teaching practices for supporting teaching-learning.

\section{RESULTS AND DISCUSSION}

We were able to implement the Teaching Triangle successfully by engaging in reciprocal classroom visits and reflection sessions. We shared our teaching materials and ideas with the other members in advance and helped them reflect on classroom teaching activities and the teacher in action. Different teaching-learning activities were utilized by the seasoned teachers and a few examples are illustrated here. One of the teachers had integrated clinical vignettes and an online discussion threading cultural competence and safety in monitoring blood and blood product transfusion through small groups of second-year undergraduate nursing students. We observed that one of our teacher members asked students to identify past experiences as examples of the content discussed. The teacher gave examples from their own practice and personal experience to illustrate the content and asked students to describe their understanding of the content and responded to student questions. We analyzed the field notes prepared by our colleagues and identified those significant notes that were necessary for motivating students to engage and to make choices when forming peer groups, giving them a sense of autonomy. Another teacher member adapted case studies and a poster synthesis threading global social work in smaller groups of third-year students. The third teacher assimilated analytical interpretations and problem-solving exercises, searching for pulmonary function tests for large groups of students in the third-year respiratory therapy program. Within four weeks after the classroom observations, the three teachers met in the post-class for a teacher-to-teacher reflection. The purpose of the meeting was to allow the teachers to debrief and share their classroom observations.

What have we learned about our teaching philosophy from each other's classroom visits?

In our outlooks, we directed our reflective practice based on the theory of backward design that starts with the end - the desired results such as goals or standards - and then derived the curriculum from the evidence of learning such as performances, and the teaching needed to equip students to perform. ${ }^{[14]}$ Our reflection on teaching and experiences from our classroom observations helped us enrich our teaching of students. We believe our students engage in digital technology and respond in varied ways to thematic based case scenario narratives. We had structured the topic's concepts with a logical progression of activities to build into the course so that we could see what it feels like from a student perspective. It was essential to set the stage for how students will be supported and how they will be reinforced.

How did we facilitate interdisciplinary teaching practices to create a community of inquiry? 
In our views, we had designed learning experiences to help transfer concepts using evidence-informed knowledge in the case studies. The integrated case study discussions engaged students to invite responses, questions, and discussions rooted in critical thinking with varying class size of 10-4080. We prepared for discussions and reflections by using content resources that are available in digital format. As the teacher, we could see the importance of problem-solving, making connections between relationships, and motivating the students to think about missing connections or reconsidering them. As dynamic teachers, we develop philosophies, beliefs, and conceptions about principles of approachability and inquisitiveness. The Teaching Triangle encouraged us to reflect on our teaching intent and gain insight into what we wanted to do. Case study discussions prompted safe, culturally appropriate dialogues, equity, and peers' inclusiveness to participate and get the most out of this learning opportunity. Students engage through critical thinking and show problem solving abilities which are vital for cognitive and behavioral learning in the class environment. ${ }^{[15]}$

We perceived that students shared topics that they have identified with and that they were keen and passionate about. We built learning activities that required personal reflection so that the students can share and reflect on each other's real thoughts. Some of the student's critical reflections in class are shown here:

One student said, "I think it was good to be faced with case studies and talk through decisions with peers for teamwork. Observing and thinking through the case study is something I could have done better at. Observing how other students make critical decisions. It was nice going through this case study approach that was new to us and that we had not been exposed to."

Another student revealed that "Working in a team was helpful for learning. Working through a clinical vignette, where events unfolded and observing how my peers discussed them, was helpful. It was nice to bounce ideas off each other and work as a team. Being in the team and working as a group helped me to understand the concepts."

One student stated, "I realized that teamwork is important, prioritizing interventions in the case study is essential. Teamwork is important to help figure out what is potentially going on in the case study. The decisions we make in the case study helped to impact my learning and thinking. Talking about problem-solving solutions while going through a clinical vignette was useful."

Another student mentioned that "Learning to tailor care around the case studies' questions as they unfold was use-

Published by Sciedu Press ful for understanding and explaining the patient's changing status. This case study helped me to learn how to think in a clinical nursing situation critically and what kind of interventions to use. Being able to converse with my peers and teacher during the problem-solving exercise was useful".

How has the experience of being in the "learner" role impacted our teaching practice?

In our perceptions, when we think of our novice undergraduate students, they engage through psychosocial and emotional domains and make connections with what makes them think critically in the case studies. The main premise of reflective practice that emerged was reciprocity. Students shared responsibility, appreciation for others' teaching, learning philosophies and practice, self-referential reflection, and mutual respect. The optimistic view of using the community of inquiry for teaching practices and learning from each other was the combined effect of professional teachers who collaborated for mutual benefit. There were challenges with student peer groups learning through detailed case studies regarding acceptance, belonging, team effort, and satisfaction. What makes a teacher approachable originated from our reflections of teachers who we admired as role models. We embraced the activity-based lessons through case study discussions with the theme of evidence-based practice that allows students to initiate interactions and allows the teacher to play the role of a facilitator of knowledge. We made decisions based on extensive experience, flexibility, versatility, preparation, and accounting for the learner needs that were encountered. We applied critical thinking connections with students when working through case studies, which made us comfortable in planning learning activities for sharing best practices. Active learning with diverse ways of learning concepts provide satisfaction and confidence with student learning using simulation and videos. ${ }^{[16]}$

Participating with interdisciplinary teachers has taught us about the following essential roles: enhancing students' motivation in learning, adapting to the needs of multicultural students, and enriching thinking processes. The Teaching Triangle helped us prepare a safe space for students to experience learning in our classrooms. A teacher's role is to instill a sense of purpose and to be the driving force behind the creation of goals, commitment to practicing change, and reflections. Interdisciplinary reflections, which were used to explore ideas through conversations around observations, thought processes, and application to our practices, were beneficial. Visiting classrooms provided a rich interdisciplinary learning experience as we built our understanding of teaching practices. We reflected on our teaching at the end of each day to look at how we could better our teaching opportunities. This self-reflection has given us a rich insight 
and a deeper understanding of teaching practices and how to be a better teacher.

What was a teachable moment as a faculty that would make my teaching more effective?

In our perspectives, we saw other members in 'live' context informed teaching practice and student interaction. While one teacher managed a large classroom very skillfully, another teacher held interactive online discussions, and the third teacher organized a collaborative poster synthesis. These teaching characteristics were attributed through peer observations, learning and assessment while trying to understand reflection-on-practice and reflection use for critical self-reflection. One of the studies, some educators exhibit confidence and positive attitudes towards engaging students with online discussions on Moodle for blending learning. [17] Reflecting on what interdisciplinary studies have shown us about good teaching and situating our understanding of teaching and learning scholarship deepens our teaching philosophy. Reflection was used to help us connect the classroom setting and students' experiences and create a meaningful understanding of the teaching. Inviting colleagues into our classrooms to watch us in action can be an intimidating but rewarding prospect. We have explored and reflected on our teaching strengths from each other's visits to our classrooms through the concept of a Teaching Triangle approach.

\section{IMPLICATIONS AND CONCLUSION}

In interdisciplinary teaching, teachers' and students' relationships and experiences are essential for students to be active learners and for teachers to provide an environment to allow active learning. Understanding students' and teachers' relationships can be helpful to plan learning experiences strategically. Interdisciplinary learning involves teacher approachability, supports student inquisitiveness, and allows teachers to anticipate many aspects of classroom behaviors to reduce or prevent unwanted behaviors more effectively. Interdisciplinary teachers who are engaged in teaching are required to actively teach and connect with students with attitudes that positively enhance knowledge and experience. Professional teachers are active thinkers and decision-makers who make instructional choices and by drawing on practically oriented and context informed practice of knowledge, thoughts, and beliefs. ${ }^{[18]}$

Two primary outcomes emerged: an increased understanding of and appreciation for teachers' work from other disciplines and formulating individual plans to enhance personal teaching centered on observations and shared reflections. We trust that sharing discussions and critical discourse with interdisciplinary teachers inspired ways to reach out, focusing on innovation and creativity in directing student learning. This reflective practice of interdisciplinary teaching opportunities contributed to our professional learning and has been a turning point for us to observe, reflect, and commit to the best teaching practices. Three aspects of interdisciplinary reflective practice that we embraced were: adopting philosophy, principles, and purpose-driven goals; facilitating teaching pedagogy and technology practices; and creating safe student learning environments. Facilitating learning with peer reflective practice of what we cannot know likened to what we do know is our commitment to change and influence our educational goals. This facilitation of teaching practice revolved around mutual discussions and sharing and reflecting on our own teaching practices that helped build awareness and understanding of the influence of teaching strategies and professional development.

The reflective practice outcomes were approachability, an equity-orientation to teaching, and research-minded inquisitiveness that mutually influenced each other. Our teaching experience demonstrated that our personal experience was the foundation from which we learnt to teach. From our teacher and class discussions, we could consolidate our journeys as professional teachers with insights from our classrooms. The benefit of the Teaching Triangle was enhancing interdisciplinary relationships, understanding of professional teaching relationships, and learning from each other without boundaries. The Teaching Triangle is a powerful strategy for improving teaching and learning in higher education and is currently gaining attention. We believe that observing our interdisciplinary teachers has inspired our educational philosophy, acclimatized us to the way of seeing our collaborative practice, and concentrated our creative thinking. It turned out to be a positive and motivating peer support by viewing our teaching practices compared to the peer teachings that we had observed. Perhaps this reflective practice of what we cannot know likened to what we do know is a steppingstone towards our intent to act and commit to change in our professional journey as an academician and educator. This interdisciplinary teaching conversations revolved around a mutual discussion, as sharing, and reflecting on teaching practices helped us build awareness as well as understand the influence of teaching strategies and professional development on ongoing improvement and best practices in teaching scholarship.

\section{ACKNOWLEDGEMENTS}

This work was supported by the Centre for Excellence in Learning and Teaching (CELT), Thompson Rivers University.

\section{CONFlicts OF INTEREST Disclosure}

The authors declare that there is no conflict of interest. 


\section{REFERENCES}

[1] Borg S. Teacher cognition in language teaching: A review of research on what language teachers think, know, believe, and do. Language teaching. 2003; 36(2): 81-109. https ://doi .org/10.1017/S026 1444803001903

[2] D'Souza MS, Isac C, Venkatesaperumal R, et al. Exploring nursing student engagement in the learning environment for improved learning outcomes. Clin Nurs Stud. 2014a; 2(1): 1-16. https: //doi.org/10.5430/cns.v2n1p1

[3] D'Souza MS, Karkada SN, Castro R. Exploring e-learning among nurse educators in undergraduate nursing. Journal of Nursing Education and Practice. 2014; 4(7): 74-84. https ://doi .org/10.543 $0 /$ jnep.v4n7p73

[4] Darby F, Lang JM. Small teaching online: Applying learning science in online classes. John Wiley \& Sons; 2019.

[5] Donohoe A. The Blended Reflective Inquiry Educators Framework; origins, development, and utilisation. Nurse Education in Practice. 2019; 38: 96-104. PMid:31234120 https ://doi.org/10.1016/ j.nepr.2019.06.008

[6] D'Souza RM, Venkatesaperumal R, Chavez F, et al. Effectiveness of simulation among undergraduate students in the critical care nursing. International Archives of Nursing and Health Care. 2017; 3(4): 1-8. https://doi .org/10.23937/2469-5823/1510084

[7] Farrell TS, Ives J. Exploring teacher beliefs and classroom practices through reflective practice: A case study. Language Teaching Research. 2015; 19(5): 594-610. https : //doi .org/10.1177/1362 168814541722

[8] Farrell TS, Mom V. Exploring teacher questions through reflective practice. Reflective Practice. 2015; 16(6): 849-865. https : //doi.org/10.1080/14623943.2015.1095734
[9] Garrison DR. Thinking collaboratively: Learning in a community of inquiry. Routledge. 2015. https : //doi .org/10.4324/978131 5740751

[10] Garrison DR, Anderson T, Archer W. The first decade of the community of inquiry framework: A retrospective. The Internet and Higher Education. 2010; 13(1-2): 5-9. https ://doi.org/10.1016/j.ih educ. 2009.10.003

[11] LaBoskey VK. The methodology of self-study and its theoretical underpinnings. In International handbook of self-study of teaching and teacher education practices (pp. 817-869). Springer, Dordrecht 2004. https ://doi.org/10.1007/978-1-4020-6545-3_21

[12] Labrague LJ, McEnroe-Petitte DM, D'Souza MS, et al. Nursing faculty teaching characteristics as perceived by nursing students: an integrative review. Scandinavian Journal of Caring Sciences. 2020; 34(1): 23-33. PMid:31062401 https://doi .org/10.1111/scs.12711

[13] Loughran J. Developing a pedagogy of teacher education: Understanding teaching \& learning about teaching. Routledge. 2013. https://doi.org/10.4324/9780203019672

[14] Palmer P. The courage to teach: Exploring the inner landscape of a teacher's life. San Francisco, CA: Jossey-Bass; 2007.

[15] Russell T. A teacher educator's lessons learned from reflective practice. European Journal of Teacher Education. 2018; 41(1): 4-14. https://doi.org/10.1080/02619768.2017.1395852

[16] Roxa T, Martensson K. Teaching and learning regimes from within In C. Kreber (Ed.), The university and its disciplines: Teaching and learning within and beyond disciplinary boundaries. New York: Routledge, Taylor, and Francis. 2009; 209-218.

[17] Schön DA. The Reflective Practitioner: How Professionals Think in Action. NY: Basic Books. 1983.

[18] Shulman LS. Teaching as community property: Putting an end to pedagogical solitude. Change. 1993; November/December 25: 6-7. https://doi.org/10.1080/00091383.1993.9938465 